\title{
ФАКТОРЫ, ОПРЕДЕЛЯЮЩИЕ ЭФФЕКТИВНОСТЬ РЕГИОНАЛЬНОЙ СИСТЕМЫ АТТЕСТАЦИИ И ПОВЫШЕНИЯ КВАЛИФИКАЦИИ ПЕДАГОГИЧЕСКИХ КАДРОВ
}

\section{FACTORS INFLUENCING THE EFFICIENCY OF THE REGIONAL SYSTEM OF CERTIFICATION AND INCREASING THE QUALIFICATION OF PEDAGOGICAL STAFF \\ I. Taaev}

Summary: This work is devoted to the consideration of the problem of the effectiveness of the teachers' certification and advanced training system in the regional educational space of the Chechen Republic. The system of working with pedagogical personnel implies not only monitoring and improving the subject training of a teacher, but also working with his personal sphere, tracking its dynamics, periods of development and stagnation, and we are talking not only about professional psychological and pedagogical training, but also about the personal meanings of himself. teacher. The factors that ensure the effectiveness of the regional system of support of the professional activity of teaching staff are identified and analyzed.

Keywords: regional system of attestation of teaching staff, efficiency, professional and personal sphere of the teacher, professional development.
A нализируя деятельность региональных систем образования, мы пришли к выводу, что в той или иной степени состояние педагогического коллектива в региональном образовательном пространстве анализировалось всегда, во всяком случае, если верить документам, этому всегда уделялось внимание. Однако тот же анализ показывает, что такого рода деятельность носит, как правило, формальный характер, завершается констатацией прохождения аттестации, осуществляется на основе и с привлечением устаревших материалов и методик. В данном случае не учитывается конечный результат в плане принятия решения о возможности дальнейшей педагогической деятельности или ее корректировке. В такой ситуации осуществляемый мониторинг теряет смысл. На наш взгляд, необходим мониторинг, сопровождаемый далее анализом состояния педагога как на личностном уровне, так и на профессиональном. За анализом должен следовать комплекс мер, позволяющих предпринять попытку корректировки состояния и профессионализма педагога. Именно в этом направлении призывают действовать документы государственного уровня, принятые в последнее время в сфере развития системы аттестации педагогических кадров, о
Таяев Ильяс Дуцаевич

старший преподаватель, Чеченский институт повышения квалификации педагогчческих работников (ЧИПКРО), г. Грозный taaevilas@gmail.com

Аннотация: Данная работа посвящена рассмотрению проблемы эффективности системы аттестации и повышения квалификации учителей в региональном образовательном пространстве Чеченской Республики. Система работы с педагогическими кадрами подразумевает не только мониторинг и совершенствование предметной подготовки педагога, но и работу с его личностной сферой, отслеживание ее динамики, периодов развития и стагнации, причем речь идет не только о профессиональной психолого-педагогической подготовке, но и о личностных смыслах самого педагога. Выявлены и проанализированы факторы, обеспечивающие результативность региональной системы сопровождения профессиональной деятельности педагогических кадров.

Ключевые слова: региональная система аттестации педагогических кадров, эффективность, профессионально-личностная сфера педагога, повышение квалификации.

которых мы говорили выше.

Естественно, это очень сложный процесс, требующий соблюдения региональной специфики, такта, уважения к педагогу, не допускающий его личностного унижения и принижения профессионального уровня. Более того, все это должно осуществляться в ситуациях, создающих максимальный комфорт для педагога.

Указанные нами ранее моменты приводят нас к заключению о том, что система работы с педагогическими кадрами подразумевает не только мониторинг и совершенствование предметной подготовки педагога, но и работу с его личностной сферой, отслеживание ее динамики, периодов развития и стагнации, причем речь идет не только о профессиональной психолого-педагогической подготовке, но и о личностных смыслах самого педагога.

С этой целью, учитывая все вышеуказанные документы, положения, факторы и обстоятельства, мы предлагаем рассматривать и развивать существующую ныне систему работы с педагогическими кадрами региона, реализуемую упомянутым выше Центром оценки ка- 
чества образования при Министерстве образования и науки Чеченской Республики, посредством перехода к планомерному созданию интегральной системы сопровождения профессиональной деятельности педагогических кадров региональной системы образования. Данная система, на наш взгляд, позволит осуществлять работу с педагогическими кадрами данного региона с научно обоснованных позиций и на систематической основе с учетом региональной специфики. Отметим, что разрабатываемая нами система, во-первых, основывается на всех вышеуказанных документах, определяющих государственную политику в области регионального образования и аттестации кадров, во-вторых, предлагает более тщательный подход к мониторингу личностной сферы педагога, его психологического и физиологического состояния и консультирование в данной сфере с учетом глубоких личностных трансформаций, которые переживает любая личность в ходе своей жизнедеятельности.

Мы разделяем мнение Н.А. Дмитриева, Л.А. Константиновой и других авторов, которые полагают, что «... сегодня каждый регион должен иметь собственную образовательную стратегию и программу развития региональной системы образования, соответствующие социально-экономическим, географическим, национально-культурным и другим особенностям» [1, с.67].

Решению указанной проблемы может способствовать предлагаемая нами система сопровождения и оптимизачии профессиональной деятельности педагогических кадров региона. Система направлена на постоянное научно обоснованное отслеживание и регулирование состояния педагогических кадров региона. Ее особенность заключается в том, что при условии ее реализации не только обеспечивается достаточный для эффективного труда уровень предметной компетентности педагога, но и отслеживается его эмоционально-психологическое состояние, изменения в личностной сфере.

В результате анализа особенностей современного регионального образовательного пространства нами были выявлены следующие факторы, обеспечивающие результативность региональной системы сопровождения профессиональной деятельности педагогических кадров:

1. научная обоснованность подходов к формированию и функционированию системы;

2. комплексность в подходе к мониторингу уровня сформированности компетенций и психофизиологического состояния педагога;

3. независимость в принятии решений о возможности и способности педагога эффективно выполнять свои профессиональные обязанности;

4. объективность в оценке уровней сформированности профессиональных и общепрофессиональных компетентностей педагога, его психофизио- логического состояния;

5. баланс необходимого и достаточного уровня сформированности компетенций для эффективной работы педагога;

6. индивидуальный подход к личности педагога;

7. соблюдение профессиональной этики и конфиденциальности;

8. учет региональной этнокультурной специфики;

9. использование новых информационных технологий в работе системы.

Научная обоснованность подходов к формированию и функционированию системы означает использование соответствующих современных научных подходов, хорошо известных и обоснованных в современном науковедении. В качестве таких подходов к разработке и реализации системы сопровождения и оптимизации функционирования педагогических кадров региона мы использовали системный, компетентностный, дифференцированный и личностно ориентированный подходы. Под системой мы понимаем совокупность объектов и связей между ними. Следовательно, в соответствии с системным подходом (И.В. Блауберг, Ф. Капра, Б.Ф. Ломов, 3.А. Решетова, Н.В. Садовский, В.М. Солнцев, Э.Г. Юдин и др.), все явления и объекты действительности рассматриваются как системы и подсистемы более высокого уровня. В нашем исследовании мы рассматриваем систему сопровождения и оптимизации функционирования педагогических кадров региона, функционирование системы как систему операций и процессов и т.д. В соответствии с компетентностным подходом мы считаем, что в основе определения возможности и способности регионального педагога эффективно и оптимально выполнять свои профессиональные обязанности лежит определенный уровень сформированности компетентности, под которой мы понимаем определенные компоненты личностной сферы педагога, связанные с профессиональной деятельностью. Профессиональная компетентность педагога-предметника определяется по уровню саморазвития и по предметному основанию тех наук, вклад которых в ее формирование считается ведущим (педагогика, методика, социальная и дифференциальная психология и т.д.). Очевидны три основных компонента компетентности как структуры: личностный, индивидуальный (или индивидуально-педагогический) и профессионально-педагогический (профессиональные знания и умения). Профессионально компетентным, по мнению А.К. Марковой, является «...такой труд учителя, в котором на достаточно высоком уровне осуществляется педагогическая деятельность, педагогическое общение, реализуется личность учителя, в котором достигаются хорошие результаты в обученности и воспитанности школьников...» [2]. Мы в своем исследовании воспользуемся определением К.Г. Юнга, который говорит о том, что «компетентность преподавателя представляет собой владение преподавателем необходимой 
суммой знаний, умений и навыков, определяющих сформированность его педагогической деятельности, педагогического общения и личности преподавателя как носителя определенных ценностей, идеалов и педагогического сознания» [3]. В соответствии с дифференцированным подходом (В.И. Андреев, Д.А. Данилов, В.В. Елисеев, З.И.Калмыкова, И.М. Осмоловская, К.Г. Селевко, М.Н. Скаткин, С.Б. Суворова, И.Э. Унт и др.), мы разработали различающиеся алгоритмы деятельности в системе для педагогов, преподающих различные дисциплины. Таким образом, дифференцированный подход позволяет нам учесть специфику предмета, которому обучает педагог, в разработке индивидуальной траектории его развития и совершенствования в профессии. Личностно ориентированный подход (Е.В. Бондаревская, В.В. Сериков и др.) к исследуемым явлениям означает ориентацию всей системы сопровождения и работы с региональным педагогом на личность, ее свойства и интересы, а также учет ее особенностей в профессиональной деятельности.

Комплексность в подходе к мониторингу уровня сформированности профессиональных компетенций и психофизиологического состояния регионального педагога означает рассмотрение уровня сформированности всех необходимых педагогу компетенций, учет возрастных изменений личностной сферы, а также психофизиологического состояния педагога. Под последним мы подразумеваем психологическую готовность и возможность педагогической деятельности. Известно, что психофизиологическое состояние человека имеет свои возрастные нормы, из которых также необходимо исходить при комплексной оценке. Психофизиологическая готовность к эффективной реализации своих функций включает психологическую готовность и физиологическую возможность. Все эти компоненты тесно связаны между собой, упущение одного из них или недостаточное внимание к нему нарушит работу всей системы. Именно комплексность позволяет оценить возможность и способность педагога выполнять эффективно свои должностные обязанности с учетом нескольких составляющих. Фактор комплексности связан также с тем, что у педагога есть всегда его теоретические знания, которые составляют основу его профессионального мировоззрения, и практический опыт, который приобретен за время работы. Естественно, что теория и практика дополняют друг друга, поэтому комплексность означает также учет как теоретической, так и практической подготовленности педагога к педагогической деятельности. Вопрос о том, какая подготовка важнее, остается открытым, поскольку фактор комплексности отрицает разделение теории и практики, подразумевает их объединение, интеграцию.

Независимость в принятии решений о возможности и способности педагога эффективно выполнять свои профессиональные обязанности означает, что такие ре- шения должны принимать специалисты, которые способны компетентно проанализировать информацию, полученную в результате прохождения педагогом системы сопровождения и оптимизации профессиональной деятельности, которые не связаны напрямую с педагогом, не работают с ним в одной образовательной организации. В другом варианте - это будет субъективное мнение, которое не позволит истинно оценить профессионализм или его отсутствие. Естественно, что, по нашему мнению, в круг таких специалистов, принимающих решение о возможности и способности педагога эффективно выполнять свои профессиональные обязанности, должны входить, прежде всего, независимые эксперты, не связанные с педагогом в профессиональной деятельности, а также обладающие достаточной компетентностью, чтобы оценить уровень компетентности, готовности и способностей педагога. Из этого логично вытекает следующий фактор.

Объективность в оченке уровней сформированности профессиональных и общепрофессиональных компетентностей педагога, его психофизиологического состояния - фактор, который означает, что при определении степени возможности и способности педагога эффективно выполнять свои профессиональные обязанности специалисты, которые будут это делать, не должны принимать во внимание никакие другие заслуги и достижения педагога, кроме результатов тестирования и работы с психологической службой. Подразумевается, что педагогики все находятся в равных условиях в ходе процедур оценки уровня сформированности их профессиональной компетентности и психологической готовности к эффективному исполнению своих должностных обязанностей. В этой системе опытный педагог со стажем находится в одинаковых условиях с молодым только начинающим свою деятельность педагогом, поскольку они проходят одинаковые процедуры диагностики. Кроме того, здесь абсолютно исключается собственное впечатление и мнение специалиста о педагоге, оно может нанести вред достоверности принимаемых решений.

Учет необходимого и достаточного уровня сформированности компетенций означает определение соответствия уровня сформированности всех компетенций уровню, необходимому для разработки и реализации всех составляющих образовательного процесса. Этот уровень устанавливается, прежде всего, стандартом, а также требованиями, предъявляемыми к педагогу на уровне региональной системы образования. Это фактор означает также разумность в подходе к отбору содержания учебной и научной информации. Конечно, всегда очень благотворно влияет на педагогическую деятельность большая эрудированность педагога, наличие более глубоких знаний по предмету, стремление расширить свои знания и общий кругозор. Однако всегда существуют границы предметной области, за которы- 
ми знания педагога считаются более широкими, чем это необходимо для эффективной профессиональной деятельности. Одновременно существует определенный уровень знаний, без которого невозможна эффективная работа педагога, тот минимум сформированности психолого-педагогических, методических и предметных компетенций, который дает педагогу возможность эффективно работать.

Индивидуальный подход как фактор эффективности региональной системы сопровождения и оптимизации функционирования педагогических кадров означает принятие того факта, что каждая личность индивидуальна, своеобразна и неповторима во всех своих проявлениях. В рамках системы сопровождения и оптимизации функционирования региональных педагогических кадров индивидуальный подход подразумевает рассмотрение результатов мониторинга уровня сформированности всех видов компетенций педагога через призму особенностей его личностной сферы.

Соблюдение профессиональной этики и конфиденциальности личной информации означает, что вся информация, касающаяся уровня сформированности всех составляющих компетентностной сферы педагога, должна быть доступна только самому педагогу и лицам, ответственным за принятие решения о возможности или невозможности выполнения им должностных обязанностей. То же самое касается информации о психофизиологическом состоянии педагога. Необходимо учитывать, что данная информация не может быть предметом обсуждения иных лиц и ведомств, за исключением специалистов, принимающих решение о дальнейшей профессиональной деятельности педагога. Кроме всего прочего, это противоречит законодательству РФ в области защиты личных данных граждан.

Фактор учета региональной этнокультурной специфики означает принятие во внимание того факта, что система образования и образовательное пространство каждого отдельного региона имеет свою специфику, связанную с этнокультурным фоном, на котором осуществляется деятельность регионального педагога [4, 5]. Эти особенности нельзя исключать из внимания, поскольку они во многом определяют деятельность педагогических кадров. Огромная территория России, многообразие национального состава населения, особенности политико-административного устройства - все эти факторы предопределили, что одной из основных структурных единиц во всероссийской системе образования может выступать регион (область, край, республика) со своей формирующейся системой образования. Выработка и проведение в жизнь эффективной государственной политики регионализации в сфере образования обусловлены как наличием в стране значительных природных, экономических, социокультурных и демографических различий, так и необходимостью в условиях рыночной экономики сбалансированного развития территориальной, производственной и образовательной систем каждого региона, превращение образования в мощный фактор социокультурного развития $[6,7]$.

Важнейшим фоктором, определяющим успешность функционирования предлагаемой системы, является использование новых информационных технологий в разработке и реализации системы [8]. Это означает:

1. создание единой универсальной базы данных региональных педагогов, позволяющей отслеживать динамику их профессионального и личностного развития;

2. разработку программного обеспечения, позволяющего определять психофизиологическое состояние регионального педагога;

3. разработку компьютерных тестов и программ для обработки результатов их выполнения для определения уровня сформированности предметной компетентности и компетенций в области психолого-педагогических наук;

4. разработка необходимого программного обеспечения для создания электронного личного кабинета каждого регионального педагога;

5. информационно-технологическое обеспечение функционирования системы.

На основе выявления и анализа факторов, способствующих результативному функционированию разработанной нами системы сопровождения и оптимизации функционирования педагогических кадров региона, нами были сформулированы следующие принципы, на основе которых осуществляется реализация системы.

1. Приниип четкого определения границ диагностируемого содержания предмета. В содержании любой учебной дисциплины есть как очень простые вещи (например, устный счет в пределах 20 в математике), так и очень сложные (гипотеза Пуанкаре и т.д.). В определении того, что из этого должно входить в компетентность педагога региональной системы образования, мы опирались на кодификатор предмета на 2017 год, подготовленный Федеральным институтом педагогических измерений (ФИПИ). Любой учебный предмет имеет бесконечное число путей развития содержания, однако, в определении материала для диагностики должны быть установлены разумные и необходимые пределы, которые позволят не только педагогу подготовиться или делать это систематически, но и составителям тестовых материалов иметь определенные ограничения материала для тестовых заданий.

2. Принцип максимально точного выявления недостаточного для профессиональной деятельности уровня сформированности предметной 
компетентности (предметных «дефицитов») в ходе диагностических исследований. Чем точнее в ходе диагностики будут выявлены пробелы в знании предмета, тем эффективнее будет работа над их устранением; так, если результатом диагностики будет вывод о недостаточном владении учителем русского языка разделом «Орфография», то этого недостаточно, чтобы педагогу проанализировать свои пробелы в знаниях. Если же результатом диагностики станет, например, информация о слабом владении темой «Правописание личных окончаний глаголов и суффиксов причастий», учитель сможет быстро ликвидировать выявленный пробел. Для этих целей применялась спецификация по предмету, позволяющая точно соотносить каждое задание в выполняемой работе с конкретной темой изучаемого раздела.

3. Принцип посильности и последовательности в работе по развитию предметных знаний. Для того, чтобы описываемая работа была результативной, она должна быть реалистичной и возможной для воспроизведения. Нужно ясно осознавать то, что учитель, испытывающий затруднения в решении задач школьного курса раздела «Арифметика», через месяц работы в проекте не будет решать задачи повышенной сложности по теории вероятности. Овладение материалом должно идти от простого к сложному, с учетом первоначально диагностированного уровня сформированности предметной компетентности.

4. Принцип реализации индивидуальной траектории работы педагога. Разница в учебной нагрузке педагога, доступности информационных и методических материалов, семейное положение, возраст, здоровье и т.п. определяют то, что динамика продвижения учителя по маршруту повышения предметной компетентности различается. В реализуемой системе учитель сам выбирает этот темп: одни из них еще работают в рамках первой диагностики, другие освоили материал второго и третьего среза. Индивидуальная траектория необходима также с целью учета особенностей личностной сферы учителя - характера, стиля восприятия информации, темперамента и т.д. Чем более индивидуализированным будет подход, тем лучше будут результаты.

5. Принцип реализации программ по совершенствованию предметной составляющей профессиональной квалификации учителя на базе школы. Действительно, предметная составляющая в компетентности учителя нуждается в развитии и совершенствовании именно там, где осуществляет свою основную деятельность педагог. Это связано, прежде всего, с тем, что, на своем рабочем месте педагог имеет больше возможностей в развитии и совершенствовании практических умений и навыков. Далее, это более привычная для него обстановка, следовательно, это снимает определенные стрессовые и напряженные моменты, например, выступление в незнакомом месте. Такие вещи кажутся обыденными, однако, из них складывается общий фон, на котором происходит развитие и совершенствование профессиональной компетентности педагога.

6. Принцип реализации программ подготовки учителя в области психолого-педагогических наук и методики обучения предмету на уровне муниципальных методических служб при непрерывном сопровождении этой работы Чеченским институтом повышения квалификации работников образования (ЧИПКРО). Общепрофессиональные компоненты компетентности педагога, связанные с владением вышеуказанными дисциплинами, связаны как с теоретическими знаниями, так и с практическими навыками работы. Что касается практических навыков, здесь педагог вполне в состоянии заниматься саморазвитием, а вот в теоретическом плане ему необходима помощь специалистов указанных служб.

7. Принцип экспертного сопровождения реализации региональной системы системы сопровождения и оптимизации функционирования педагогических кадров экспертами и специалистами Чеченского государственного педагогического университета как профильного вуза для подготовки специалистов в области педагогических наук. Участие таких специалистов, имеющих, прежде всего, навыки теоретической подготовки, необходимо, поскольку именно указанное образовательное учреждение занимается профессиональной подготовкой специалистов педагогического профиля.

8. Принцип объективности означает, что на основании тестирования, исследования компетентностной сферы и психофизиологического состояния педагога региональной системы образования делаются выводы о возможности педагога выполнять свои должностные обязанности, данные выводы не зависят от воли и желания кого-либо еще. Объективность в данном случае означает независимость мнения лиц, принимающих решение о возможности или невозможности дальнейшей профессиональной деятельности регионального педагога, от администрации образовательного учреждения, в котором работает педагог, от коллектива, в котором он работает. Объективность предполагает также независимость мнения специалистов-психологов и специалистов вуза, привлекаемых к участию в работе системы.

9. Принцип соблюдения анонимности результатов, неперсонифицированный свод и анализ данных. Персональные данные учителей кодируются, результаты педагогов, участвующих в проекте, из- 
вестны только им самим. Администрация школы, органы управления образования не получают конкретную информацию о персональных результатах диагностики того или иного педагога, этим занимается специальная служба, независимая от школьных административных органов, находящаяся в распоряжении органов управления региональным образованием.

10.Принцип доступности и наглядности формы представления результатов. Результаты диагностики необходимо представлять в простой, интуитивно понятной и наглядной форме. Учителю важно видеть не только свой текущий уровень результатов, но и его динамику. Естественно, что в данном случае речь идет об активном использовании в реализации предлагаемой системы новых информационных технологий, которые позволяют, во-первых, оптимизировать работу, во-вторых, обеспечить конфиденциальность необходимых данных, в-третьих, отслеживать динамику какихлибо изменений.

11. Принцип научной и теоретической обоснованности реализуемых мероприятий. Мы полагаем, что в основе разработки и реализации абсолютно всех мероприятий, связанных с предлагаемой нами системой, должны лежать определенные научные подходы, которые должны соответствовать современной научной картине мира, то есть тем научным взглядам, которые характерны для со- временного этапа развития научного знания, для современной образовательной парадигмы.

Таким образом, рассмотрение факторов, определяющих эффективность системы, образовательной среды, в которой она будет функционировать, а также принципов ее функционирования, позволило предложить систему аттестации и повышения квалификации региональных педагогических кадров, которую мы назвали системой сопровождения профессиональной деятельности педагогических кадров региона. Термин «сопровождение» в данном случае отражает основную задачу системы и сразу настраивает, прежде всего, на сотрудничество с педагогом на всех этапах реализации системы, подразумевая сознательное отношение педагога к необходимости анализа своей деятельности для определения ее эффективности и результативности. Термин «профессиональная деятельность» говорит о нацеленности системы на определение состояния компетентностной сферы личности регионального педагога, прежде всего, ее профессиональных составляющих. Но совершенно понятно, что она не может быть проанализирована в отрыве от психофизиологического состояния педагога. Нам представляется, что данное название системы лучше всего отражает ее сущность и целевые установки. Реализация предлагаемой системы сопровождения функционирования педагогических кадров региона с соблюдением указанных принципов позволит добиться желаемых результатов и обеспечит результативность региональной системы образования.

\section{ЛИТЕРАТУРА}

1. Дмитриев Н.А., Константинова Л.А. Региональная система образования и управление ее развитием на основе программно-целевой модели // Известия ТулГУ. Гуманитарные науки. 2014. №4-2. С.65-70.

2. Маркова А.К. Психология труда учителя. М.: Просвещение, 1993. С. 67.

3. Писаренко, В.И. Методология инновационного образования в контексте динамики общенаучной картины мира [Текст] / В.И. Писаренко // Известия ЮФу. Педагогические науки. - 2008. - № 5. -С. 13-21.

4. Арсалиев, Ш.М-Х. Методология современной этнопедагогики / Ш.М-Х. Арсалиев. - М.: Гелиос АРВ, 2013. - 320 с.

5. Арсалиев, Ш.М-Х. Этнопедагогика в контексте современной научной парадигмы [Текст] / Ш.M-X. Арсалиев. - Palmarium Academic Publishing. Deutschland. 2013. -285 c. ISBN 978-3-659-98363-4.

6. Арсалиев, Ш.М-Х., Мусханова И.В. Экспериментальная проверка модели этнопедагогизации формирования личности в образовательном пространстве Чеченской Республики // Вестник Орловского государственного университета. Серия: Новые гуманитарные исследования. - 2012, №3(23). - С. 102-106.

7. Арсалиев, Ш.М-Х., Писаренко, В.И. Моделирование этнопедагогических технологий в контексте современной научной картины мира / Ш.М-Х. Арсалиев, В.И. Писаренко // Вестник Чувашского государственного педагогического университета им. И.Я. Яковлева. 2015.№1(85). С.79-84.

8. Ахметова Д.Н. Специфика взаимодействия с информационным полем в информационно-коммуникативной профессиональной деятельности // Человеческий фактор: проблемы психологии и эргономики. 2007. Т. 2. № 3. С. 26-27. URL: http://elibrary.ru/item.asp?id=13367490 (дата 0бращения: 01.07.2020).

9. Белогуров А.Ю. Философско-педагогические аспекты изучения процесса регионального образования // Бюллетень Владикавказского института управления. 2004. № 11-12. С. 241-265.

( ) Тааев Ильяс Дуцаевич (taaevilas@gmail.com). 